\title{
La creación de la Semana indianista. Indianidad, Folklore y Nación en Bolivia $^{1}$
}

\section{Cecilia Wahren ${ }^{2}$ \\ Universidad de Buenos Aires, Buenos Aires, Argentina ${ }^{3}$ \\ wahrencecilia@gmail.com}

Recibido: 17 de junio de 2013

Aceptado: 23 de septiembre de 2013

\footnotetext{
1 Artículo de reflexión que resulta de los avances de la investigación doctoral en curso "Raza, Nación y formación de alteridades: La representación del "indio" en el proceso de construcción de la identidad nacional boliviana (1899-1932)" realizada en la Universidad de Buenos Aires.

2 Becaria doctoral del Concejo Nacional de Investigaciones Científicas y Técnicas de la República Argentina (CONICET).Candidata a Doctora en Historia de la Universidad de Buenos Aires.

3 Investigadora del Instituto de Ciencias Antropológicas de la Universidad de Buenos Aires.
} 


\title{
La creación de la Semana indianista. Indianidad, Folklore y Nación en Bolivia
}

\section{Resumen}

Durante la primera mitad del siglo XX se produce en Bolivia una redefinición de los contornos de la identidad nacional. A lo largo de este periodo, signado por la rebelión indigena liderada por Zarate Willka en 1899, el espectro de la guerra racial y la migración aymara hacia la ciudad de La Paz dieron lugar a la reconfiguración de las nociones de indio y de raza. El presente artículo aborda estas transformaciones desde una perspectiva histórica a través del estudio de la denominada Semana indianista organizada en 1931. Analiza específicamente la influencia que la condensación de expresiones artísticas, intelectuales y rituales públicos que pusieron en escena elementos indigenistas, tuvo en la reconfiguración de la noción de raza y su concomitante transformación en las concepciones de bolivianidad, indianidad y folklore, contribuyendo a la conformación de representaciones ambivalentes, propias de las particularidades del indigenismo boliviano de comienzos del siglo XX.

Palabras clave: Nación, Raza, Indianidad, Folklore, Bolivia.

Palabras clave descriptores: Identidad nacional, Indigenismo, Nacionalismo y cultura, Folclor, Bolivia, Siglo XX

\section{The Creation of the Indianist Week. Indianness, Folklore and Nation in Bolivia}

\begin{abstract}
During the first half of the twentieth century in Bolivia a redefinition of the contours of national identity occured. Throughout this period, marked by the indigenous rebellion led by Zarate Willka in 1899, the specter of the race war and the Aymara migration to the city of La Paz resulted in the reconfiguration of the notions of Indian and race. This article discusses these changes from a historical perspective through the study of the so-called Indianist Week organized in 1931. It specifically analyzes the influence that the condensation of artistic, intellectual and public rituals, which staged indigenous elements, had in the reconfiguration of the concept of race and its concomitant transformation of the conceptions of Bolivian identity, Indianness and folklore, contributing to the formation of ambivalent representations, typical in the particularities of the Bolivian indigenism from the early twentieth century.
\end{abstract}

Keywords: Nation, Race, Indianness, Folklore, Bolivia.

Key words plus: National Identity, Indigenity, Nationalism And Culture, Folklore, Bolivia, Siglo XX

\section{A criação da Semana indianista. Indianidade, Folclore e Nação na Bolivia}

\section{Resumo}

Durante a primeira metade do século XX produz-se na Bolívia uma redefinição dos contornos da identidade nacional. Ao longo deste período, marcado pela rebelião indígena liderada por Zarate Willka em 1899, o espectro da guerra racial e a migração aimara para a cidade de La Paz deram lugar à reconfiguração das noções de índio e de raça. Este artigo aborda essas transformações desde uma perspectiva histórica através do estudo da nomeada Semana indianista organizada em 1931. Especificamente analisa a influência que a condensação de expressões artísticas, intelectuais e rituais públicos que encenaram elementos indigenistas teve na reconfiguração da noção de raça e sua concomitante transformação nas concepções de bolivianidade, indianidade e folclore, contribuindo à conformação de representações ambivalentes, próprias das particularidades do indigenismo boliviano de começos do século XX.

Palavras-chave: Nação, Raça, Indianidade, Folclore, Bolivia.

Palavras-chave descritores: Identidade nacional, Indianidade, Nacionalismo e cultura, Folclore, Bolivia, Siglo XX. 


\section{Introducción}

Las preguntas sobre quiénes son los indios y cuáles son el significado e implicancias de dicha denominación han suscitado intensos debates en el mundo académico a partir sobre todo, de la visibilización de los sujetos indigenas y la conformación de organizaciones indianistas a comienzos de la década de 1970.

La obra pionera de Bonfil Batalla ha definido la categoría de indio como un producto de la situación colonial que designa al sector colonizado y lo caracteriza como diferente e inferior con respecto al sector colonizador desde una perspectiva que abarca la dimensión racial, cultural, intelectual y material (Bonfil, 1988, p. 19). A partir de este planteamiento, aportes más recientes han mostrado cómo los mismos procesos que transforman las diferencias culturales en marcas de subordinación, cristalizando nuevas jerarquías y estableciendo un discurso hegemónico (Pacheco de Oliveira, 2006, p. 8), simultáneamente han procurado borrar el hecho de que esas particularidades no se vinculan con especificidades preexistentes sino con la condición de ser pueblos colonizados (Wade, 2000, p. 22).

En este sentido, el sociólogo peruano Aníbal Quijano ha planteado que la invención de la noción de raza fue el mecanismo que permitió presentar las ideas de superioridad-inferioridad que implica toda relación de dominación, como diferencias de naturaleza y de este modo, logró invisibilizar su carácter histórico (Quijano, 1992). Para Quijano la imposición de la idea de raza como elemento de clasificación social funciona como piedra angular del patrón de poder que él denomina colonialidad. Quijano definió la colonialidad como el elemento constitutivo del patrón mundial de poder capitalista que se origina y mundializa a partir de la conquista de América. Este se funda en la imposición de una clasificación racial/étnica de la población, operando en todos los ámbitos materiales y subjetivos.

El nuevo patrón de poder origina nuevas identidades sociales (indios, negros, aceitunados, amarillos, blancos, mestizos) y geoculturales (América, África, Lejano Oriente, Cercano Oriente, Occidente y Europa). Asimismo impone el eurocentrismo como única racionalidad válida y como emblema de la modernidad (Quijano, 2007). Siguiendo esta perspectiva de análisis, la diferencia entre colonizador y colonizado concebida en términos raciales constituye un elemento estructural indispensable dentro del sistema de dominación y de hecho 
la permanencia de la categoria de indio es testimonio y agente de la reproducción de la colonialidad en contextos de Estados-nación.

El rol de la idea de raza dentro de las configuraciones de las naciones latinoamericanas han dado lugar a una vasta bibliografia ${ }^{4}$ que desafia el carácter homogeneizante de la Nación como creadora de vínculos horizontales que postuló la producción académica de la década de 1980 (Anderson, 1993; Gellner 1991). Los autores que centraron sus estudios en los procesos de construcción de las naciones latinoamericanas han visualizado cómo el mismo proyecto nacional también construye la diferencia de manera activa (Wade, 2008, p. 376). En este sentido, al mismo tiempo define vínculos horizontales y verticales, recreando jerarquías al interior de la comunidad nacional (Alonso, 1994).

Si las elites criollas que controlaron los Estados republicanos aspiraron, por un lado, a construir una Nación según la experiencia europea, es decir, buscando la homogeneización de una población encerrada en las fronteras del Estado; por otro lado, reconfiguraron las clasificaciones raciales heredadas de la colonia en función de las cuales la gran mayoría de la población designada como negros, indios o mestizos quedó impedida de tomar alguna participación en la generación y en la gestión del proceso estatal (Quijano, 2006, p. 18). De este modo, los nuevos Estados independientes quedaron articulados a sociedades profundamente coloniales, lo cual obstaculizó el proceso de democratización de la sociedad, condición básica para su nacionalización, truncando el sueño de las elites criollas de emular el modelo eurocéntrico del moderno Estado-nación (Quijano, 1992).

A lo largo de la historia de los estados nacionales latinoamericanos, la diferencia entre colonizador y colonizado concebida en términos raciales constituye entonces un elemento estructural indispensable dentro del sistema de dominación y de hecho, la permanencia de la categoría de indio es testimonio y agente de la reproducción de la colonialidad en contextos de Estados independientes. Sin perder esta connotación colonial, la noción de indio ha sido dotada de diversos sentidos a lo largo de la historia.

$\mathrm{El}$ indigenismo desplegado en América Latina a partir de la década de 1920 marcó un momento de redefinición de esta noción. En sus diferentes vertientes (política, literaria, académica) así como en sus diferentes espacios nacionales, el indigenismo comparte un objetivo final

4 Entre ellos se encuentran los estudios de Alonso (2008), Appelbaum, Macpherson y Rosemblatt (2003), De la Cadena (2008), Quintero (2009), Poole (2000), Segato (2010), Sanjines (2005) y Wade (2000). 
que es la integración de los indios (Bonfil, 1988). Este objetivo aparece como una de las soluciones que a lo largo del siglo XIX y principios del XX se proponen para resolver el problema del indio, enunciación que expresa, en realidad, la contradicción en la que se encuentran sumergidos los Estados latinoamericanos al constituirse en Estados independientes con sociedades coloniales (Quijano, 2000).

La aspiración integradora del indigenismo deviene entonces de la necesidad de ensanchar los límites de la Nación incorporando al otro antes excluido, en un contexto de movilización social que exigía buscar principios alternativos de legitimidad ante la aparición de nuevos sectores sociales que amenazaban como potenciales disruptores del orden (Funes, 2006, pp. 137, 324), pero sin renunciar a la idea de Nación exclusivista y étnicamente homogénea. De este modo, se admite (más bien se denuncia) el pluralismo étnico como un hecho, pero no como una condición deseable para el futuro (Bonfil, 1988). Esta es justamente la ambigüedad de dicha ideología que propone como meta proteger la especificidad indígena al mismo tiempo que busca una integración que disuelva la adscripción étnica en el ser nacional (Morín, 1988).

La primera mitad del siglo XX, contexto en el cual se despliega el indigenismo en Bolivia, es un período signado por una preocupación centrada en la redefinición de los contornos de la comunidad nacional y del rol del indio dentro de ella que se desprende de la rebelión indígena librada al interior de la Guerra Federal ${ }^{5}$. El espectro de la guerra racial y la intensa migración aymara hacia la ciudad confluyeron en intensos debates que dieron lugar a la reconfiguración, tanto de la noción de indio como de la misma noción de raza.

La influencia del darwinismo social presente a fines del siglo XIX, comenzó a decaer y los proyectos de Nación que excluían al indio de la comunidad nacional y demandaban un proceso inmigratorio al mismo tiempo que condenaban a la raza india a la desaparición, fueron reemplazados por representaciones alternativas que, tal como lo describe Larson a partir de los estudios de Nancy Stepan, dieron lugar a un racismo

5 La Guerra Federal se originó en un enfrentamiento regional al interior de la elite que desembocó en el triunfo y ascenso al poder de la elite liberal paceña y el traslado de la capital boliviana de Sucre a La Paz. Para este triunfo fue crucial la alianza entre el partido liberal y las comunidades aymaras que, a raíz de la ofensiva que la ley de ex-vinculación significó para las tierras de las comunidades, vieron en la alianza con el partido liberal la posibilidad de retornar al antiguo pacto de reciprocidad entre el ayllu y el Estado. Pero si bien en un principio los indígenas actuaron bajo las órdenes del Ejército Federal, a medida que se desarrollaba la contienda, se desató un proceso de radicalización que desafió fuertemente la soberanía del Estado Boliviano. Una vez finalizada la guerra, la elite liberal paceña, encumbrada en el poder, emprendió una serie de políticas represivas sofocando la rebelión indígena que se había gestado al interior de su propio levantamiento (Condarco, 1983; Mendieta 2007). 
flexible que a través de las nuevas teorias del determinismo medioambiental abría la posibilidad de ascenso y progreso racial (Demélas, 1981; Larson, 2008) ${ }^{6}$. El "problema del indio" se vuelve entonces un problema pedagógico, y durante las dos primeras décadas del siglo XX se elaboran múltiples proyectos educativos que buscan la integración subordinada del indio en calidad de soldado, minero y agricultor, pero excluido de toda participación política (Larson, 2008).

La Semana indianista se inserta en este ejercicio de inclusión del indio dentro de la Nación boliviana, pero va mas allá de su mero reconocimiento y se propone celebrar la indianidad como componente básico del folklore nacional, en el mismo proceso que define y delinea las propias nociones de indianidad y folklore. En este capítulo abordaremos el estudio de dicho evento a la luz de estas problemáticas preguntándonos en qué medida y de qué modo influyó esto en la reconfiguración de la Nación y de la indianidad en Bolivia durante las primeras décadas del siglo XX.

\section{La asociación Amigos de la Ciudad y la organización de la Semana indianista}

La Semana indianista fue un evento organizado por la asociación Amigos de la Ciudad, una institución cívica de La Paz originada en 1916 cuando se forma el Grupo Cívico Tawantinsuyo y formalmente en 1928, cuando toma el nombre de Amigos de la Ciudad. La asociación, conformada por paceños ilustres, postuló como objetivos contribuir al progreso de la ciudad a través del desarrollo económico industrial y urbano y al mismo tiempo, realzar y defender los valores tradicionales. En este sentido, a la vez que se proponía dotar a La Paz de jardines y parques y de embellecer sus calles ensanchándolas para transformarla en una ciudad pujante y moderna, se postulaba a sí misma como forjadora de ideales e incluso como orientadora de la política gubernamental (Miranda, 2006). La asociación estaba signada por el reciente traslado de la sede de gobierno de Sucre a La Paz y por ello estos objetivos se veían influenciados por la necesidad de consolidar la imagen del departamento y su proyección nacional.

\footnotetext{
Stepan (1991) introduce este concepto al analizar el modo en que las especificidades del discurso eugenésico en latinoamérica habilitaron diversos modos de concebir un progreso racial a través de reformas sociales higienistas y sanitarias. En la aplicación que Larson realiza del término a la realidad boliviana de comienzos de siglo XX, la definición de racismo flexible excede las reformas sociales meramente higienistas y se centra principalmente en los proyectos pedagógicos.
} 
La actividad de esta institución a la que dedicaremos el capítulo surgió a partir de la iniciativa de Alberto de Villegas, un abogado paceño que se desempeñó también en el campo de las letras y la arqueología. Formó parte de la Sociedad Geográfica de La Paz, de la entidad Amigos de la Ciudad y fue director del Museo Tihuanacu, en donde inició una gestión que significó la renovación y puesta en valor de las ruinas y la cultura tihuanacota. Si bien la vinculación de sus obras con temas indigenistas fue tardía, su producción periodística, así como su actividad en el museo y principalmente su rol de organizador principal de la Semana indianista, le otorgaron el calificativo de indianista auténtico (Archivo de La Paz, Fondo Alberto de Villegas). En 1931 Villegas impulsó la organización de la denominada Semana indianista con los objetivos de "exaltar el folklore nacional", "engrandecer el alma racial" y "forjar una auténtica cultura boliviana con raigambre indoamericana" (Archivo de La Paz, Fondo Alberto de Villegas)

¿Qué significado tiene en Bolivia la organización de un evento que celebre la indianidad no solo en sí misma sino como un componente fundamental del folklore nacional? ¿Qué se entiende y qué se propone como indianidad y folklore en dicho evento? ¿Qué finalmente, expresa esto acerca de la representación del indio en Bolivia durante la década de 1930? Para acercarnos a la respuesta de estos interrogantes comenzaremos por describir brevemente en qué consistió aquel evento iniciado en 1931, una semana en que la indianidad fue el foco de expresiones musicales, teatrales, y pictóricas y el eje de numerosas conferencias. Asimismo, fue escenario para un despliegue simbólico en el que se inauguró un salón indianista desde el cual se exhibía la wiphala ${ }^{7}$, se organizaron desfiles con la participación de caciques apoderados y tuvo como uno de los ejes centrales la puesta en valor de Tiahuanacu como raíz de la bolivianidad.

Abordaremos el evento de la Semana indianista desde diferentes aspectos que configuran varias aristas que presentan las representaciones de Nación e indianidad de la década de 1930. En primer lugar estudiaremos las discursividades que se desplegaron durante el evento. En el siguiente apartado analizaremos el modo en que el proceso de apropiación de Tiahuanacu como la raíz de la bolivianidad estableció una cadena específica de significados entre indianidad, folklore y Nación. En tercer lugar observaremos los motivos que la música y el arte pictórico imprimieron a dicha representación y por último analizaremos la participación de Eduardo Nina Quispe dentro de la semana

\footnotetext{
7 Bandera utilizada por algunas etnias andinas, entre ellas la aymara.
} 
indianista y su trayectoria como apoderado nos permitirá vislumbrar la articulación existente entre las representaciones hegemónicas de indianidad y Nación y las planteadas por un sector particular del movimiento indígena.

A lo largo de cada uno de los apartados se desbrozará el modo en que se constituyen en mutua interacción las concepciones de indianidad, bolivianidad y folklore, contribuyendo a su vez a delinear una noción de raza que permitió redefinir los criterios de inclusión/exclusión dentro de la comunidad nacional. La reconstrucción se hará a partir de un cuerpo heterogéneo de fuentes (documentación estatal, folletería y correspondencia de asociaciones civiles, ensayos literarios, prensa) que nos permitirá acercarnos a dicha temática desde diversos soportes que manifiestan distintas dimensiones de una misma problemática.

\section{Ensayos y conferencias: la invención de lo autóctono}

Durante toda la Semana indianista se realizaron una serie de conferencias dictadas en el salón indianista, al cual se podía concurrir gratuitamente. Las conferencias también eran transmitidas por radio. Asimismo, los periódicos La Razón y Última Hora además de reproducir muchas de ellas, dedicaron números especiales a la celebración de la indianidad que se desplegó en aquel entonces publicando ensayos, obras literarias y artículos.

En la correspondencia emitida por Amigos de la Ciudad aparecen numerosas convocatorias a intelectuales y miembros de distintas instituciones para dictar una conferencia "sobre un tema netamente autóctono" (Archivo de los Amigos de La Ciudad La Paz, Correspondencia, 1931). En las conferencias encontramos una tensión entre una visión que plantea al indio como una amenaza y descansa en la integración indígena como problema pedagógico y otra que desliza el denominado problema del indio a la esfera de lo material. Se insertan de este modo, dichas visiones en las diversas interpretaciones sobre el problema del indio que convivian en tensión en la intelectualidad de la década de 1930.

Alineado con la primera visión, José Salmón se refiere a la "poderosa raza del altiplano" como un componente esencial de la Nación boliviana que a pesar de la opresión colonial y republicana, ha logrado sobrevivir. La denuncia de la opresión que vive el indio forma parte de una advertencia sobre la fortaleza de la población aymara: 
Parece que estuviéramos esperando que la amargura llene los pechos de los aymaras, para que, exasperados despierten rugientes y feroces como león herido. Y este día no está lejano (...) El abandonar estos problemas y no resolverlos a tiempo es fomentar trastornos sociales y politicos, que el país debe evitar a toda costa. Y si no ponemos el remedio con oportunidad, los izquierdistas, por una parte, y por otra el comunismo indigenal se encargará de darnos en el porvenir algunas sorpresas. Por nuestro descuido o incompetencia, el indio escribirá mañana la historia de Bolivia. (Salmon, 1931, p.11)

En esta conferencia el indio aparece como amenaza, tanto por la violencia irracional que ha caracterizado al estereotipo de indio decimonónico y de los juicios que condenaron a los participantes de la rebelión acontecida durante la Guerra Federal, como por la articulación entre el movimiento de caciques apoderados y el comunismo, cuyo antecedente más reciente lo constituía la rebelión de Chayanta. La solución al problema del indio así concebido se retrotrae a los proyectos pedagógicos desplegados desde los primeros años del siglo XX que, junto a la creación de un patronato nacional del indio, debian atender las condiciones particulares de la población indígena y contribuir a "mejorar la cultura en su medio" (Salmon, 1931, p.11). En este sentido se ubica también su denuncia del pongueaje ${ }^{8}$ que, al conducir al indígena a la ciudad, lo corrompe por alejarlo del espacio rural al que pertenece.

Entre quienes se ubican en la segunda visión se encuentra Bellón Rivero. Para él, el indio es un factor de progreso pero requiere un previo proceso de adaptación para el cual es necesario "descender del campo de la ideología al de las realidades. (...) Es por eso que el problema del indio, más bien lo llamariamos el "problema agrario"' (Ultima Hora, 1931, 28 de diciembre). El indio como "raza explotada" y el problema del indio como "problema agrario" es un argumento que se esgrime en varios ensayos".

Abraham Valdéz profundiza este anterior planteamiento. El autor reflexiona en torno a los conceptos de indiofilismo, indigenismo e indianismo, denunciando el indiofilismo como "la corriente superficial de los pseudo protectores, humanitarios y románticos, que hacen del indio motivo de feria y discurso", propone al indigenismo como la campaña que reivindica el derecho que tiene el indio al dominio y posesión

8 Sistema de explotación por el cual los miembros de las comunidades indígenas estaban sometidos a brindar periódicamente trabajo servil a los propietarios de las haciendas.

9 Nos referimos a los ensayos "Una raza explotada" y "Sobre la psicología del indio altiplánico" publicados en el periódico Ultima Hora (1931, 24 de diciembre). 
de la tierra (Ultima Hora, 1931, 21 de diciembre). Es por eso que "los intentos de solucionar este problema por la educación, la filantropía legislativa o humanitaria, han naufragado frente al interés latifundista del político criollo, del clero, de todos los explotadores del indio".

Para Valdéz solamente la doctrina marxista puede encaminar la solución al problema del indio ya que lo identifica con el problema de la tierra y su reivindicación. Desde allí interpreta el "agrarismo del indio" y su "sentido religioso emergente de la "madre tierra" que obliga a considerar al indio de forma inseparable con respecto a su tierra (Ultima Hora, 1931, 21 de diciembre).

La tensión presente entre interpretaciones de adscripciones tan disímiles no excluye sin embargo, confluencias entre estos pensamientos pues comparten la idea de que el indio es un componente esencial de la Nación boliviana, que de todos modos requiere un proceso de adaptación, ya sea desde el plano educativo o desde su condición material de existencia. Esta noción propia del racismo flexible tan extendido en la intelectualidad de la época, es inescindible de otro elemento compartido por estas interpretaciones: la influencia del medio en la conformación de la indianidad.

Esta noción de indianidad se encuentra más extendida aún en la conferencia de cierre de la Semana indianista dictada por Roberto Prudencio, titulada "Ideas sobre el sentido de la cultura altiplánica", Prudencio pasa de la idea de raza vinculada al medio a centrar la atención directamente en este último y ya no solo en relación con el indio sino principalmente en relación con la Nación. Reflexionando acerca del despliegue acontecido durante la Semana indianista, cuyo principal objetivo era la creación de un arte nacional, Prudencio realza la idea de Nación homogénea como un "estilo único", un "sentido cósmico" que constituye la unidad nacional y que no es otra cosa que "el fruto innato de la tierra" (Ultima Hora, 1931, 29 de diciembre). Es por eso que en un contexto en el que "no somos ya europeos, pero tampoco en verdad americanos" es necesario descubrir ese sentido cósmico que emana de la tierra para poder llegar a poseer una cultura autóctona.

Prudencio describe la tierra como una enorme altiplanicie que impregnó de una angustiosa lejanía a la cultura tihuanacota, así como lo hace ahora con la cultura boliviana, "un fenómeno geográfico más que suficiente para producir un sentido vital particular y único" (Ultima Hora, 1931, 29 de diciembre). En esta descripción el indio, "habitante autóctono de esta tierra", no es más que un elemento del paisaje de la altipampa. El autoctonismo identificado con el altiplano, funciona 
aquí no solo como condición de indianidad sino como amalgama para crear una comunidad nacional. En este sentido, en la conferencia de Prudencia se circunscribe al indio al medio rural y simultáneamente se proyecta al paisaje paceño como el paisaje propiamente boliviano.

\section{Actualizando el pasado: la excursión a Tiahuanacu}

El solitario monolito de la pampa es el símbolo del indio. Representa mucho pero no hace nada" (La Razón, 1931, 29 de diciembre).

Es posible tener un primer acercamiento a la excursión a Tiahuanacu a través de la vivida descripción que Humberto Frías hace de ella en una publicación del diario Ultima Hora. Allí, Frías comienza describiendo el paisaje que se ve desde el tren que devora las grandes distancias de la Pampa. El paisaje severo apenas tiene variantes, tan solo a lo lejos se destacan "ruinas erguidas como soldados solitarios". Como parte de él aparece una "muchedumbre abigarrada de indios y bailarines en inmensa algazara". Es, para Frías, de tal magnificencia que "los cerros rocosos forman a Tiahuanacu un anfiteatro gigantesco donde aparece adivinarse una grandiosa civilización" (Ultima Hora, 1931, 24 de diciembre).

Ese paisaje alberga un pueblo de fiesta, que agita banderas nacionales. Alberga, también, a los bailarines indigenas:

[...] ahí están los choquelas que llevan en la cabeza unos extraños sombreros de plumas rojas, ahí están los quenales, los chunchos [...] La llanura tihuanaquense se ha poblado de sones (...); música exótica, bailes de aquellos lejanos tiempos conservados por milagros. (Ultima Hora, 1931, 24 de diciembre)

Por último, nos muestra la participación de dos "apóstoles del indianismo": Alberto de Villegas, con su infatigable esposa que luce un "hermoso traje indigena que la asemeja a una flor de kantuta", y Felipe Pizarro que explica el significado de aquella romería y que "acaso por primera vez hurga en el corazón de los aimaras, para despertar lo que aún queda de tradicional y de verdaderamente indígena". El paisaje vuelve a protagonizar la descripción, se amalgama a la palabra de aquel hombre y se ve por un instante "en la linde de los cerros oscuros 
la forma inmensa del colla, erguirse en un esfuerzo supremo para contemplar a sus últimos descendientes" (Ultima Hora, 1931, 24 de diciembre).

La excursión a Tiahuanacu fue una de las actividades a las que más importancia se les asignó en la planificación de la Semana indianista. Este evento constituye uno de los primeros que difunden y presentan a Tiahuanacu como la raíz de la identidad nacional boliviana. Incongruente con el discurso decimonónico que deseaba borrar la presencia indígena de la comunidad nacional, esta nueva concepción que busca ensanchar la Nación tanto en términos sociales como temporales, extiende sus raíces alli donde imagina un origen glorioso en la raza superior tihuanacota (Posnansky, 1945). Nos interesa en este apartado, desentrañar los objetivos y la organización que condujeron a la condensación de sentidos que quedan reflejados en la descripción de Humberto Frías. Para ello podemos detenernos en algunos fragmentos de su relato.

Detrás de los "bailes de aquellos lejanos tiempos conservados por milagros" realizados en las mismas ruinas por indígenas, existió una articulación de diversos actores sociales con el fin de llevar a cabo la actuación. Central fue la participación institucional de prefectos y corregidores. A partir del pedido de Amigos de la Ciudad, los bailes fueron garantizados por el corregidor de Tiahuanacu bajo órdenes del Prefecto del departamento (Archivo de los Amigos de La Ciudad La Paz, Correspondencia, 1931). La Unión Obrera Tihuanacu respondió también a la solicitud de Amigos de la Ciudad enviando "danzantes autóctonos con indumentaria nativa" y asegurando la "concentración de escolares de niños indígenas, de las comunidades y ex-comunidades de la compresión de Tiahuanacu" (Archivo de los Amigos de La Ciudad La Paz, Correspondencia, 1931).

Por otra parte, la elección de los indígenas que realizaron la exhibición de bailes en Tiahuanacu estuvo a cargo de personalidades de la comunidad científica e intelectual. Al respecto, Federico Buck indicó que "sería bueno procurar asistan los de Yanarico, propiedad del señor Juan Prudencio, los de Antamarca, Unamarca y Rosapata, propiedad del coronel Sanjinés, por tener tropas interesantes de bailes antiguos" (Archivo de los Amigos de La Ciudad La Paz, Correspondencia, 1931). La interpretación de esa actuación también estuvo mediada por la participación de Rigoberto Paredes, quien tuvo el rol de explicar "la significación e importancia folklórica de los bailes indigenistas" (Archivo de los Amigos de La Ciudad La Paz, Correspondencia, 1931). 
De este modo, se despliega una performance en la que se establece un lazo de continuidad entre las comunidades indígenas contemporáneas y el pasado tihuanacota, reificando los bailes indígenas y convirtiéndolos, así, en parte del folklore nacional.

Esta operación se repite y se plasma claramente a través de una imagen que circuló como portada del programa de la excursión y de las invitaciones. En esta imagen la superposición de individuos indígenas en la puerta del sol, el símbolo más fuerte de la grandeza de la sociedad tihuanacota, cumple la función de hacer pasar a dichas personas como vestigios de ese pasado al mismo tiempo que las ruinas cobran actualidad y significación para la Bolivia contemporánea.

\section{Semana Indianista}

\section{ROMERIA HISTÓRICA A TIAHUANACU}

Domingo 20 de Diciembre de 1931.

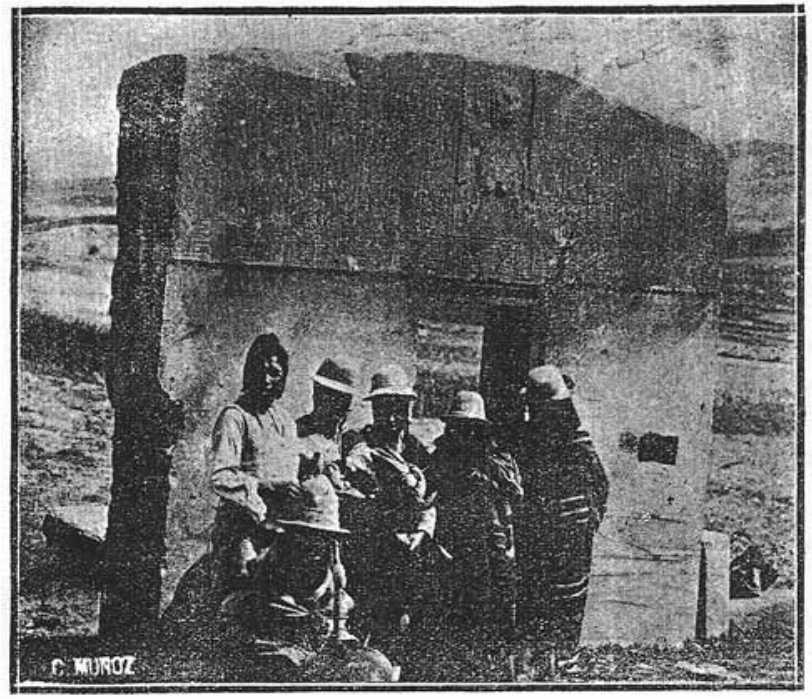

La maravillosa puerta del sol.

Imagen 1: Programa de la Semana indianista, 1931. ALP/AdeV.

La articulación de distintos actores sociales fue necesaria también para armar "aquel maravilloso paisaje" que, como describe Frías, sirvió de "anfiteatro" para la romería. Fueron recurrentes las cartas para arreglar la puerta del sol, poner en condiciones las inmediaciones de las ruinas principales y para decorar el sitio con plantas de kantuta, 
retama y kiswara. La metáfora que describe a la mujer de Villegas como una planta de kantuta no es casual. Esa planta había sido la flor imperial y luego fue declarada flor nacional por el Estado boliviano.

En la romería a Tiahuanacu la planta de kantuta es incorporada como componente de un ambiente que, así como en los ensayos y conferencias de los intelectuales, cobra en la descripción de Frías un rol protagónico que remite a un origen autóctono. Las flores de kantuta (que por ser propias de las yungas no se adaptan al clima del altiplano y luego deben ser reemplazadas) fueron suministradas por distintas personalidades e instituciones y formaron parte del esfuerzo por mejorar el escenario (es decir, el lugar donde se representa una ficción) de la romería (Archivo de los Amigos de La Ciudad La Paz, Correspondencia, 1931).

¿Cuál es el objetivo de esta puesta en escena tan cuidadosamente diseñada? ¿Cuáles son sus efectos de sentido? Como hemos planteado anteriormente, el producto de esta conjugación de elementos fue establecer una unidad y superposición de símbolos que tuvieron como efecto una actualización del pasado a través de los bailes indígenas y sus fotografias junto a las ruinas, en un ambiente cuidadosamente diseñado y proyectado como el elemento autóctono de la Nación.

La destinataria de esta puesta en escena fue, no solo la sociedad boliviana, sino -y principalmente-, la comunidad internacional. Hubo una intensa preocupación porque pudieran asistir los diplomáticos presentes en Bolivia. La Oficina de Turismo Municipal asumió la organización del evento junto con Amigos de la Ciudad con el propósito de "impulsar la cultura nacional en uno de sus más interesantes aspectos, como es el de divulgar la importancia de las ruinas de Tiahuanacu mediante visitas periódicas de turistas" (Archivo de los Amigos de La Ciudad La Paz, Correspondencia, 1931).

Así las cosas, podemos plantear que en este marco en el cual "no somos ya europeos, pero tampoco en verdad americanos", los intentos por fijar un origen autóctono para la Nación boliviana colocan a Tiahuanacu como testimonio de una gran civilización cuya herencia sobrevive en el aymara del altiplano, latente, esperando ser despertada (La Razón, 1931, 27 de diciembre). En esta operación, que hacia el exterior quiere delinear lo propiamente boliviano y al interior crear "en la conciencia del pueblo el sentido [del] verdadero valor [de Tiahuanacu]", entra en juego tanto la comunidad científica como las distintas instituciones estatales. La participación de la población indígena está supeditada a las órdenes de prefectos y corregidores, y circunscripta a actuar como vestigios del pasado que condensan el espíritu nacional. 
Tal es la ausencia de agencia que tiene en esta celebración de la indianidad la población indigena que en el relato de Frías es Felipe Pizarro, reconocido intelectual y estudioso de la educación bilingüe, quien "hurga en el corazón de los aimaras, para despertar lo que aún queda de tradicional y de verdaderamente indígena." Es desde esta concepción de la indianidad que es posible definir al "solitario monolito de la pampa como símbolo del indio", y al indio como símbolo de la Nación.

\section{La música y la pintura en la definición de un arte nacional}

Cuando en las alturas tristes y desiertas de las bolivianas frígidas mesetas oyen los viajeros el son de las quena, pasa por sus almas la vaga tristeza que sobre las ruinas y páramos dejan las últimas notas, las últimas penas de los pueblos idos y las razas muertas (Ultima Hora, 1931, 24 de diciembre)

Las expresiones artísticas son quizás uno de los ámbitos que mejor permiten visualizar la relación entre indianidad, folklore y nación. $\mathrm{Si}$ en los aspectos estudiados previamente un elemento puede aparecer desligado del otro, en el caso de la pintura y la música y la obsesión por definir los motivos folklóricos bolivianos redundarán en un programa de producción del arte nacional a través del cual es posible discernir el modo en que fueron articulados.

Beatriz Rossels postula que en Bolivia la música ha adquirido el carácter de:

[...] "símbolo nacional por excelencia" en tanto constituye el patrimonio de mayor relevancia para la gran mayoría de sus pobladores, en mayor grado que la literatura, las artes plásticas y otros tipos de expresión, pues al no tener acceso a las formas escritas del arte, a causa de su analfabetismo, [...] las masas han volcado en la música una enorme riqueza artística y documental. (Rossels, 1996, p. 15)

La autora analiza el arduo camino que la música popular transita hasta constituirse en música nacional en la década de 1920 cuando compositores, cantantes, comentaristas de medios de comunicación y el público en general le asignan un valor representativo. Teniendo 
en cuenta la contradicción presente en la elite liberal que oscila entre el rechazo y la adopción de la música indígena como componente de la Nación, Rossels focaliza en su trabajo las "raíces fundamentalmente indigenas" de la música nacional boliviana. En este sentido, más allá del proceso de blanqueamiento que en este devenir pudiera sufrir la música indígena, la autora se propone buscar "el mapa nocturno" de la cultura popular convertida en nacional, es decir, los elementos indígenas que perviven en ella (Rossels, 1996, pp. 18-19).

Rossels plantea que si bien la música nacional aparece como signo de los conflictos raciales y de clase, el mundo indígena se introduce en ella, convirtiéndola en un terreno de profundos puntos de contacto entre los mundos existentes en Bolivia. La música nacional funciona así, como un símbolo ritual, referencial y de condensación de las ideas de Nación, territorio y población y está saturada de cualidades emocionales que se manifiestan en las fiestas y ceremonias privadas y públicas. De este modo, es capaz de lograr la integración ritual a nivel consciente e inconsciente de individuos y grupos, constituyendo el único símbolo nacional que atraviesa el país horizontal y verticalmente, del campo a la ciudad, entre las diferentes regiones y al interior de las clases sociales, en un movimiento completo de ida y vuelta (Rossels, 1996, pp.116-117). En este sentido, la autora concibe a la música como un elemento que conforma una identidad nacional efectivamente existente, en el cual confluyen, en una mutua influencia, elementos indigenas, criollos y mestizos.

En este apartado nos interesa analizar específicamente aquello que la autora llama proceso de blanqueamiento, que en este caso se refiere al proceso que la música indígena debe transitar para convertirse en música nacional. De todos modos, partir de la premisa de una música indígena resulta ya problemático, pues será justamente en el mismo proceso en que se define lo nacional que también se define lo netamente indigena. Si bien este es un fenómeno que excede el evento que aquí analizamos, estudiaremos las operaciones que aparecen alli en este sentido.

Un evento central de la Semana indianista fue la Velada de arte nativo llevada a cabo el 24 de diciembre. La importancia asignada a este número quedó plasmada en la numerosa correspondencia emitida en función de sus preparativos. Las representaciones musicales, que ocuparian un rol central dentro de la velada, consistian en "arreglos sobre motivos indígenas" interpretadas por la Filarmónica $1^{\circ}$ de Mayo (Archivo de La Paz, Fondo Alberto de Villegas, Programa de la Gran Velada de Arte Nativo). Un terceto de cuerdas tocaría "varios 
yaravies netamente incaicos" (Ultima Hora, 1931, 4 de diciembre) y se presentarian numerosas obras de distintos estilos musicales (Vals, Bolero, Fox Trot, Huayño) compuestas por músicos académicos en base a diseños indigenistas. Estas representaciones estaban unidas a lo largo de la velada, a conferencias que explicitaban y delineaban el sentido del despliegue artístico (Archivo de La Paz, Fondo Alberto de Villegas, Programa de la Gran Velada de Arte Nativo).

Otro modo de acercarse a la comprensión del rol de la música en la Semana indianista es a partir de las retretas militares. Como plantea Rossels, las retretas fueron la gran contribución del Estado a la música popular al constituirse, en el siglo XIX y en la primera mitad del siglo XX, en los núcleos mejor dotados para la ejecución y divulgación nacional, ya que trasladándose de un confin a otro del territorio nacional, tuvieron impacto en la población, difundiendo repertorios y popularizando melodías (Rossels, 1996, pp. 108-110). En la Semana indianista las retretas fueron de gran importancia y condujeron a intensificar la articulación entre el ejército y la Asociación Amigos de la Ciudad. En esta ocasión, la variedad de motivos interpretados por las bandas militares quedó reducida a "motivos autóctonos estilizados [que pudieran] cimentar una cultura artística tomando como base la riqueza de nuestro folklore." (Archivo de los Amigos de La Ciudad La Paz, Correspondencia, 1931). Por otra parte, estas retretas debian "comprender música exclusivamente nacional, de preferencia sobre motivos musicales folklóricos de diferentes autores" (Archivo de los Amigos de La Ciudad La Paz, Correspondencia, 1931).

En ambas manifestaciones aparece lo autóctono, lo indígena o incluso lo incaico, como la materia prima a partir de la cual se crean motivos estilizados que, en todas las ocasiones son interpretados por músicos académicos o por la banda del ejército. A este proceso de estilización subyace una búsqueda previa de lo netamente autóctono que espera encontrarse de manera pristina en algún sitio. El reducto donde se imaginó hallarlo fueron las escuelas indigenales rurales. Los periódicos anunciaron:

[...] la Escuela normal indigenal [...] hará conocer al público por primera vez sus canciones del folklore. Esta actuación ha de constituir seguramente una novedad pues se trata de piezas originales con música autóctona y letra adecuada para los establecimientos de enseñanza rural. (La Razón, 1931, 25 de diciembre) 
Esta noción de música autóctona aparece esbozada por la misma escuela indigenal. En una carta dirigida a Alberto de Villegas, Alfredo Guillén Pinto rogaba que fuera aceptada su intervención en la Semana indianista. Lo que su escuela estaba en condiciones de ofrecer eran "sus canciones propias, originales, no conocidas aún por nadie, con música netamente vernácula" (Archivo de La Paz, Fondo Alberto de Villegas). La música netamente autóctona corresponde entonces a la ruralidad, donde ha permanecido oculta hasta que por fin sale a la luz como parte de un proceso de redención del indio impulsado por la elite letrada, representación que encarna en los proyectos educativos que asignaban a la población indígena escuelas-talleres en el campo. En este sentido, podemos plantear que la obsesión por encontrar la música autóctona desemboca en su invención, la invención de un elemento inalterado circunscripto al ámbito rural que pervive en el indígena. Es por esto que es de carácter nostálgico, triste, y el sonido de la quena se yergue como un lamento.

Ahora bien, volviendo al interrogante sobre la relación entre indianidad, folklore y nación ¿cuál es el lugar que ocupa la indianidad dentro del folklore?, ¿y el folklore dentro de la música nacional? Para responder a este interrogante es pertinente adentrarse en el concurso de música nacional que también organizaba la Asociación Amigos de la Ciudad. Las bases del concurso clasificaban la música del siguiente modo:

- $\quad$ Folklórica -h) Melodías indígenas; yaravies; huaynos; caluyos; chayanteñas; mecapaqueñas; y otras danzas indígenas de las diferentes regiones del país; himnos

- Folklórica estilizada: -i) Marchas; foxtrot; Valses; Romansas; canciones de himnos; suites; preludios; etc.

- Criolla: -j) Bailecitos de tierra; cuecas bolivianas; boleros bolivianos; carnavalitos y pasacalles; etc.

- Nacional: -k) Tema libre; suites; minuets; himnos; canciones; valses; fox-trot; marcha (Archivo de los Amigos de La Ciudad La Paz, Correspondencia 1933)

En este ejercicio de diferenciación y clasificación, la música indígena es concebida como parte del folklore, mientras que la música nacional engloba elementos del denominado folklore estilizado hasta prácticamente coincidir. Aquí se encuentra formalizado el proceso de estilización que hace de la música indígena la raíz de la música nacional y al mismo tiempo la diferencia de esta. Mientras la música folklórica estilizada y la música nacional aparecen como ámbitos 
de creación vigentes, la música indígena es la pieza escondida en el altiplano que recuerda "las últimas notas de los pueblos idos y las razas muertas". Esta idea encuentra una clara expresión en la exposición de instrumentos autóctonos que luego de cumplir su rol en la Semana indianista irian a constituir parte de la colección del Museo de Tiahuanacu (Archivo de los Amigos de La Ciudad La Paz, Correspondencia 1931). Así, mientras el sitio de la música nacional es el teatro, el del folklore indígena es el museo.

Esta doble operación de apropiación y deslinde con respecto a los elementos culturales indígenas se hace posible gracias al proceso de estilización que funciona como vector de un blanqueamiento de estos elementos. Las representaciones estilizadas, enmarcadas en el Teatro Municipal y ejecutadas por renombrados artistas, poco recuerdan a aquella "música exótica conservada por milagros" descrita por Frías que sí era interpretada por comunarios en la excursión a Tiahuanacu. En este sentido, si la música efectivamente constituye un elemento de integración nacional no funciona, como plantea Rossels, como una fusión de diversos elementos que se influyen reciprocamente, sino que se proyecta una nueva creación que delimita y jerarquiza las expresiones culturales. ¿Es posible entonces, a partir de esta concepción de música nacional basada en un folklore estilizado, hablar de la existencia de un mito del mestizaje en Bolivia? Dentro de la ambivalencia que presenta la invención de la Nación boliviana, parece que una arista se trasluce, aquí, en ese sentido.

La misma operación de estilización se encuentra presente en el arte pictórico. El comité de la Semana indianista invitó "a todos los artistas, nacionales y extranjeros, a concurrir a la exposición con el nombre de "Salón Indianista" [...] cuyo objeto es ponderar los elementos y los valores artísticos autóctonos". La exposición comprendería las secciones de pintura, dibujo, grabado, escultura, música, artes decorativas, fotografia, cinematografia" y las obras presentadas debian estar "exclusivamente consagradas a un tema indigenista" (Ultima Hora, 1931, 30 de noviembre). Esta convocatoria general se dirigió especialmente a los alumnos y profesores de la Academia de Bellas Artes (Archivo de los Amigos de La Ciudad La Paz, Correspondencia 1931).

La participación de los artistas también estuvo relacionada con la confección de motivos decorativos que pudieran impregnar a la sociedad boliviana de su sentido vernáculo. En este sentido, la sola Puerta del Sol de Tiahuanacu constituía: 
[...] un vivero inagotable de motivos de arte decorativo, sin hablar de todos los fragmentos dispersos de la estupenda civilización de Tiahuanacu y de los mil motivos estéticos de nuestro altiplano [...] prodigioso patrimonio artístico, incomprendido o desdeñado. (Archivo de La Paz, Fondo Alberto de Villegas)

Esta iniciativa se insertaba en un marco en el que se veía necesario acercarse:

[...] al hermano indio, comprender las inquietudes de su espiritu y aprovechar los materiales que nos brinda para echar las bases de una cultura sólida, que no viva más de imitaciones serviles ni de cosas transplantadas [...] [y que pueda estribar] nuestro orgullo, nuestra fortaleza y nuestro originalidad, en ser precisamente descendientes de indios. (El Diario, 1931, 13 de diciembre)

Nuevamente radica en el mundo indigena la raíz del arte autóctono, considerado, aquí, como fuente de elementos decorativos que puedan integrar la simbología nacional. La elite debía rescatar este arte y propa-

garlo no solo hacia dentro de la ciudad de La Paz, sino y principalmente, presentarlo a la comunidad internacional como elemento que constituye la singularidad boliviana. Pero al mismo tiempo esa singularidad nacional comienza a asociarse a una identidad regional indoamericana. De ahí la correspondencia a prefectos de Cuzco, Arequipa y Puno, con el fin de invitar a artistas de tendencia indianista a concurrir y enviar productos, con el fin de "impulsar el arte americano entre los pueblos que formaron el Gran Tihuantinsuyu y afianzar, al mismo tiempo, la unión decretada por la prehistoria, la historia y la geografia" buscando "formular votos por que Bolivia y el Perú, realicen conjuntamente una labor de reivindicación del indio" (Archivo de los Amigos de La Ciudad La Paz, Correspondencia 1931).

\section{Del indio autóctono al indio salvaje: la participación de Eduardo Nina Quispe en el desfile de caciques-apoderados}

Uno de los eventos de la Semana indianista que se diferencia de los anteriores en cuanto a la participación indigena es el desfile de caciques apoderados. El diario La Razón del 27 de diciembre anunciaba que los indígenas de la República Collasuyo, 
[...] han organizado, gracias a la actividad del popular Eduardo Nina Quispe y de varios caciques y curacas llegados últimamente de provincias, un desfile del elemento autóctono masculino y femenino, que se realizará (...) en la Plaza Murillo. (La Razón, 1931, 27 de diciembre)

La participación de Nina Quispe, protagonista de la lucha jurídica indigena de la primera mitad del siglo XX, en un desfile en la semana indianista, con su concomitante exotización y folklorización, refleja el complejo entramado de subjetivación presente en el tejido que compone el sistema de dominación que opera en Bolivia en la década de 1930.

Eduardo Nina Quispe era parte del movimiento de caciques apoderados que se había formado al amparo de la disposición de la ley de ex-vinculación de 1874 que permitía a las comunidades delegar en apoderados la gestión de sus reclamos de tierras (Choque y Quisbert, 2010 , p. 27). Nina Quispe provenía de una comunidad que había sido expropiada durante las revisitas que se realizaron entre 1905 y 1915. Cuando los excomunarios intentaron recuperar sus tierras comunales en 1920, Nina Quispe tuvo que huir a La Paz para evitar la represión policial (Gotkowitz, 2012, p. 85). Alli organizó la Sociedad República del Qullasuyu y paralelamente el Centro Educativo Qullasuyu. Estas instituciones servian, no solo para actividades educativas, sino también para realizar gestiones relativas a la reivindicación de las tierras comunitarias de origen y denunciar especialmente los abusos de las autoridades locales.

Por otra parte, la residencia de Nina Quispe en La Paz le permitió relacionarse con las autoridades gubernamentales y establecer contacto con líderes indígenas de diferentes puntos del país (Choque y Quisbert, 2010, pp. 44-46). Es durante esta estadía que Nina Quispe participa del desfile organizado para la Semana indianista, formando parte de la única ocasión en que los indígenas participan de manera activa en un evento predominantemente impulsado por la elite criolla. ¿Cuál fue el motivo de dicha participación? ¿Refleja esto una introyección de la imagen reificada del indio?, ¿o constituye en cambio un margen de negociación dentro del evento?

En una solicitud enviada a la Cámara de Diputados el 31 de diciembre de 1931, Nina Quispe expresa que se encuentra "hondamente conmovido el espíritu de la raza indigena, por la feliz iniciativa de dedicar una semana, como homenaje a nuestra raza" (Archivo Histórico de la Asamblea Legislativa, Solicitud de indígenas con informes. Caja 
$\mathrm{N}^{\circ}$ 93. Informe $\mathrm{N}^{\circ}$ 28). El objetivo de dicha solicitud no es sin embargo, transmitir gratitud por la organización de la Semana indianista, sino el reclamo porque "desaparezca por completo el trato brutal, el abuso y el atropello al indio (...) Queremos que haya más humanidad más comprensión, más piedad para nuestra clase, si quiera por un sentimiento de egoísmo nacional" (Archivo Histórico de la Asamblea Legislativa, Solicitud de indigenas con informes. Caja $\mathrm{N}^{\circ}$ 93. Informe $\left.\mathrm{N}^{\circ} 28\right)$.

El oficio enviado por Nina Quispe contraponía así a la celebración de la indianidad folklorizada, la denuncia por las expoliaciones sufridas contemporáneamente por la población indígena. Expresa también, el carácter de la práctica política de Nina Quispe que planteaba un reconocimiento explícito de los ritos e instituciones republicanas en tanto "sugería que el reconocimiento del territorio y la autonomía indigenas podían ser la base para el avance de la Nación" (Gotkowitz, 2012 , pp. 86, 87), al mismo tiempo que sus demandas de restitución territorial constituian también, proyectos de autodeterminación política (Gotkowitz, 2012, p. 85). Esta dualidad refleja la complejidad del movimiento indígena en La Paz, que oscilaba entre la inclusión y la subversión de los preceptos del Estado boliviano en un contexto en que La Paz se convertía en lugar de refugio y de protesta para los excomunarios, así como escenario de una aimarización que dio lugar a una inédita interacción cotidiana entre las elites paceñas y la población aymara (Larson, 2008, pp. 121-122).

Esta configuración influyó también en las representaciones que las propias elites forjaron de los indígenas en la década de 1930. Señalar el devenir de la actividad de Nina Quispe luego de su participación en la Semana indianista permite visualizar este aspecto. En noviembre de 1932, a solo un año de celebrado el desfile, Nina Quispe aparece como protagonista de la organización de una sublevación indígena en el departamento de la Paz. La prensa dedicó un puntilloso seguimiento de aquella "ya que el caso referente a sublevaciones indigenales es de palpitante actualidad y entraña un peligro grave" ( $L a$ Razón, 1932, 5 de noviembre). Al respecto el diario La Razón publicó:

[...] habían acordado la sublevación con tendencias comunistas, haciendo su propaganda mediante volantes impresos y en los cuales, se hacia saber que toda la clase indígena se encontraba lista para la sublevación general [...] y que en cuanto se diera el grito de alarma todos estaban en la obligación de organizarse y pasar a degüello a los blancos, para así apoderarse de todas las tierras que constituían 
fincas que en esa forma había ordenado su presidente Nina Quispe. (La Razón, 1932, 5 de noviembre)

La imagen de una potencial amenaza indígena, presente en los abordajes pedagógicos del problema del indio, e invisibilizada a través de su folklorización en la excursión a Tiahuanacu y en las expresiones artísticas, aparece aquí como una amenaza real y como respuesta, se introduce la idea de la guerra de razas protagonizada por la imagen del indio salvaje dispuesta a "pasar a degüello a los blancos". En este sentido, la representación forjada tan cuidadosa y minuciosamente a lo largo de la Semana indianista de un indio autóctono, rural, vestigio del pasado y fuente de motivos decorativos, convivía con la imagen del indio salvaje presente durante todo el siglo XIX. Como demuestra la cercanía de estos eventos, ambas representaciones podian utilizarse alternativamente como modos distintos de clasificación de la población indígena al interior de la comunidad nacional boliviana. En este sentido, la idea de indio salvaje no constituye un resabio decimonónico sino la contracara de la imagen del indio autóctono.

\section{Conclusiones}

No es posible reconstruir acabadamente los cambios que las representaciones del indio y de la Nación sufren en Bolivia en la década de 1930 a partir, exclusivamente, del análisis de la Semana indianista. De todos modos, en ella se produce una condensación de sentidos a partir de la cual es posible delinear las nuevas connotaciones que adquiere alli la indianidad.

La articulación íntima que existe entre Amigos de la Ciudad y el Estado boliviano, desde los orígenes de la asociación, está presente en la Semana indianista en la dotación de recursos y en la apertura y participación de múltiples instituciones y autoridades nacionales y municipales. Inserta en este andamiaje institucional, la actividad de la asociación se integraba al proceso de consolidación de la estructura departamental que buscaba reafirmar la legitimidad de La Paz como sede de gobierno.

El proyecto municipal de Amigos de la Ciudad se entronca, así, con la pretensión de redefinir los contornos de la identidad nacional, en la que los diacríticos paceños se proyectan como nacionales tanto hacia el interior como hacia el exterior de Bolivia. Si al interior se busca lograr 
un alcance nacional a través de la invitación a corregidores y prefectos de los distintos departamentos, hacia el exterior se presenta la distinción boliviana hacia la comunidad internacional convocando a diplomáticos y embajadores, al mismo tiempo que se construye una identidad indoamericana articulándose con intelectuales y artistas indigenistas latinoamericanos.

Ahora bien, ¿cuáles son esos diacríticos? En la semana indianista aparecen reunidas interpretaciones en pugna y distintos lenguajes y modos de transmisión que van confluyendo al verse atravesados y a la vez ir conformando una noción de lo autóctono que folkloriza a la población indígena como parte de una estrategia de apropiación que, hacia el interior, busca neutralizar la agencia indígena, y hacia el exterior, pretende presentar la singularidad boliviana. Homogeneidad y singularidad son los dos elementos que signan la redefinición de la indianidad y la Nación, reconstruidas ambas a partir de un nuevo estereotipo del indio que lo fija en un determinado lugar: parte del paisaje de la altipampa, resabio del pasado, o simplemente un elemento decorativo que debe sufrir un proceso de estilización para constituirse en nacional.

Si bien muchos de estos elementos se explican como parte de una redefinición regional de las identidades nacionales en torno al indoamericanismo, los elementos que constituyen el indigenismo boliviano se articulan en un contexto específico en el que la representación del indígena se construye en relación, por un lado, a una profunda dependencia de la elite criolla con respecto a la mano de obra indígena y por otro, a un fuerte reclamo de autonomía de las comunidades que se expresa a través de recurrentes sublevaciones que avivan el fantasma de la rebelión de 1899.

Por otra parte, a diferencia del Perú, donde el indigenismo cusqueño surge como parte de un autoctonismo andino que se contrapone al modernismo limeño (De la Cadena, 2004), en Bolivia el indigenismo se gesta en la misma capital, que se presenta como depositaria del autoctonismo y como centro modernizador. Es por esto que la ambivalencia propia de todo pensamiento indigenista (Franco, 1990) se profundiza en el caso boliviano. Esta ambivalencia del indigenismo boliviano es lo que explica la existencia de un discurso que oscila entre el mito del mestizaje, la apropiación folklorizada de lo indigena y la visión del indio salvaje.

La asociación presente en la Semana indianista entre indianidad y folklore constituye un elemento importante que re-articula las tensiones 
de una sociedad signada por la colonialidad del poder. La celebración de la indianidad en un evento que busca realzar el alma racial boliviana constituye así, una operación de incorporación de lo indígena como parte del folklore nacional en un doble movimiento que integra pero también delimita y jerarquiza los distintos elementos culturales. En este movimiento, la profunda ambivalencia del indigenismo y de su influencia en el imaginario nacional, impide cristalizar las representaciones homogeneizantes que proyecta una elite que busca en el indígena lo autóctono, pero al mismo tiempo se concibe a sí misma como racialmente diferente de él.

\section{Referencias}

Anderson, B. (1993). Comunidades imaginadas. Reflexiones sobre el origen y la difusión del nacionalismo. México: FCE.

Alonso, A. (1994) The Politics of Space, Time and Substance: State Formation, Nationalism, and Ethnicity. Annual Review of Antropology, 23, 379-405.

Alonso, A. M. (2008). El "mestizaje" en el espacio público: estatismo estético en el México Posrevolucionario. En De la Cadena, M. (Comp.) Formaciones de indianidad. Articulaciones raciales, mestizaje y Nación en América Latina (pp. 173-196). Popayán: Envión editores.

Appelbaum, N., Macpherson, A. y Rosemblatt, A. (2003) Race and Nation in Modern Latin America. Chapel Hill: The University of North Carolina Press.

Archivo de los Amigos de La Ciudad La Paz , Correspondencia, 1931-1933.

Archivo de La Paz, Fondo Alberto de Villegas.

Archivo Histórico de la Asamblea Legislativa.

Bonfil, G. (1988). Utopía y Revolución. El pensamiento politico contemporáneo de los indios en América Latina. México: Nueva Imagen.

Bonfil, G. (1992). Identidad y pluralismo cultural en América Latina. Buenos Aires: Fondo Editorial del CEHASS.

Condarco, R. (1983). Zárate el "Temible" Willka. Historia de la rebelión Indígena de 1899 en la República de Bolivia. La Paz: Renovación.

Choque, R. y Quisbert, C. (2010). Líderes indigenas aymaras. Lucha por la defensa de tierras comunitarias de origen. La Paz: UNIH-PAKAXA.

Demélas M. D. (1981). Darwinismo social a la criolla. Historia Boliviana, 1, 55-82.

De la Cadena, M. (2004). Indígenas mestizos: raza y cultura en el Cusco. Lima: IEP.

De la Cadena, M. (Comp.) (2008). Formaciones de indianidad. Articulaciones raciales, mestizaje y Nación en América Latina. Popayán: Envión editores. 
Franco, C. (1990) Impresiones del indigenismo. Hueso Húmero, 26, 44-68.

Funes, P. (2006). Salvar la Nación: intelectuales, cultura y politica en los años veinte latinoamericanos. Buenos Aires: Prometeo.

Gellner, E. (1991). Naciones y nacionalismo. Madrid-Buenos Aires: Alianza.

Gotkowitz, L. (2012). La revolución antes de la Revolución. La Paz: Plural-PIEB.

La Razón (1931, 27 de diciembre).

La Razón (1931, 29 de diciembre).

Larson, B. (2008). La invención del indio iletrado: la pedagogía de la raza en los Andes bolivianos. En M. De la Cadena (Comp.). Formaciones de indianidad. Articulaciones raciales, mestizaje y Nación en América Latina (pp. 117-147). Popayán: Envión Editores.

Mendieta, P. (2007). De la alianza a la confrontación: Pablo Zárate Willka y la rebelión indigena de 1899 en Bolivia. Lima: UNMSM.

Miranda Baldivia, R. (2006). Contenido y semblanza de Amigos de la Ciudad. Amigos de la Ciudad, 6-7.

Morín, F. (1988). Indianidad, etnocidio, indigenismo en América Latina. México: Instituto Indigenista Interamericano.

Pacheco de Olveira, J. (Comp.). (2006). Hacia una antropología del indigenismo. Estudios críticos sobre los procesos de dominación y las perspectivas politicas actuales de los indigenas en Brasil. Río de Janeiro/Lima: Contra Capa/CAAAP.

Poole, D. (2000). Visión, raza y modernidad. Lima: Edición del Sur.

Posnansky, A. (1945). Tiahuanacu. La cuna del hombre americano. Nueva York: J.J. Augustin.

Quijano, A. (1992). Raza, etnia y nación en Mariátegui: cuestiones abiertas. En R. Forgues (Ed.). José Carlos Mariátegui y Europa (pp. 167-187). Lima: Amauta.

Quijano, A. (2000) Colonialidad del poder, eurocentrismo y América Latina. En E. Lander (Comp.). La colonialidad del saber, eurocentrismo y ciencias sociales (pp. 219-264). Buenos Aires: CLACSO.

Quijano, A. (2006) El movimiento indígena y las cuestiones pendientes en América Latina. Argumentos, 50, 51-77.

Quijano, A. (2007). Colonialidad del poder y clasificación social. En S. Castro Gómez y R. Grosfoguel (Comps.), El giro decolonial (pp. 93-126). Bogotá, Siglo del Hombre.

Quintero, P (2009). La colonialidad del poder y el mito de la democracia racial en Venezuela. En M. Ayala y P. Quintero (Comps.) Diez años de revolución en Venezuela. Historia, balance y perspectivas (1999-2009) (pp.203-238). Buenos Aires: Maipue. 
Rossells, B. (1996). Caymari Vida: la emergencia de la música popular en Charcas. Sucre: Editorial Judicial.

Salmón, J. (1931). El indio escribirá mañana la historia de Bolivia. La Paz: Atenea.

Sanjinés, J. (2005). El espejismo del mestizaje. La Paz: IFEA.

Segato, R. (2010). Los cauces profundos de la raza latinoamericana: una relectura del mestizaje. Crítica y Emancipación, 3, 11-44.

Stepan, N. (1991). The Hour of Eugenics. Race, Gender and Nation in Latin America. Londres: Cornell University Press.

Ultima Hora (1931, 4 de diciembre).

Ultima Hora (1931, 21 de diciembre).

Ultima Hora (1931, 24 de diciembre).

Ultima Hora (1931, 28 de diciembre).

Wade, P. (2008). Identidad racial y nacionalismo: una visión teórica de Latinoamérica. En De la Cadena, M. (Ed.) Formaciones de indianidad. Articulaciones raciales, mestizaje y nación en América Latina (pp. 367-385). Popayán: Envión editores.

Wade, P. (2000). Raza y Etnicidad en Latinoamérica. Quito: Abya-Yala. 